\title{
Preparation and Thickness Optimization of Graphenic-Based Carbon Material as a Microwave Absorber
}

\author{
Affandi Faisal Kurniawan ${ }^{1,2}$, Mohammad Syaiful Anwar ${ }^{1}$, \\ Khoirotun Nadiyyah ${ }^{1}$, Yana Taryana ${ }^{3}$, Muhammad Mahyiddin Ramli ${ }^{4}$, \\ Mashuri $^{1}$, Triwikantoro ${ }^{1}$ and Darminto ${ }^{1, *}$ \\ ${ }^{I}$ Advanced Materials Research Group, Department of Physics, Institut Teknologi Sepuluh Nopember, \\ Sukolilo, Surabaya 60111, Indonesia \\ ${ }^{2}$ Department of Physics Education, Universitas PGRI Semarang, Semarang 50232, Indonesia \\ ${ }^{3}$ Research Center for Electronics and Telecommunication, Indonesian Institute of Sciences (LIPI), \\ Bandung, Indonesia \\ ${ }^{4}$ School of Microelectronic Engineering, Universiti Malaysia Perlis, Pauh Putra Campus, \\ Arau 02600, Perlis, Malaysia
}

("Corresponding author's e-mail: darminto@physics.its.ac.id)

Received: 22 August 2020, Revised: 3 May 2021, Accepted: 22 June 2021

\begin{abstract}
The purpose of this study is to optimize the thickness of a layered graphenic-based carbon compound, which is a non-magnetic material derived from biomass (old coconut shell). After the sample was exfoliated using $\mathrm{HCl}$ solution, the morphological structure showed that the material used in this study is a reduced graphene oxide (rGO), similar to carbon but with a thickness of less than $10 \mathrm{~nm}$ and lateral size in submicron $(100 \mathrm{~nm})$. The sample with a $2 \mathrm{~mm}$ thickness was then characterized using a vector network analyzer (VNA) to measure its reflection loss $(R L)$. The measurement result is evaluated by converting the S-parameter values $\left(\mathrm{S}_{11}\right.$ and $\left.\mathrm{S}_{21}\right)$ from the VNA using the Nicolsson Ross Weir (NRW) method to obtain input variables such as relative complex permeability and relative complex permittivity. Following this, the single-layer thickness of the sample was optimized using a genetic algorithm (GA), which can predict the appropriate thickness so that the optimum $R L$ can be obtained. The optimum thickness of the sample was found to be $3.48 \mathrm{~mm}$, which resulted in a much higher $R L$. The $R L$ was re-measured for verification using a sample with the corresponding optimized thickness, revealing that this optimization is feasibly operational for a radar absorbing material (RAM) design.
\end{abstract}

Keywords: Genetic algorithm, NRW method, Graphenic, Old coconut shell, Thickness optimization

\section{Introduction}

The X-band frequency region of the electromagnetic spectrum has various uses; for example, it can be used in satellite communications [1,2], radar aperture synthetic, ground moving target indicators, maritime surveillance [3], and medical accelerators [4]. The X-band electromagnetic spectrum can also increase electromagnetic interference (EMI). The presence of EMI can disrupt the use of devices that use the X-band electromagnetic waves. The interference of the X-band frequency can be reduced by an efficient radar absorber, which can absorb at least $90 \%$ of the overall power of the band [1]. Some aspects that need to be considered while designing a radar absorber material (RAM) include relative complex permeability $\left(\mu_{\mathrm{r}}\right)$, permittivity $\left(\varepsilon_{\mathrm{r}}\right)$, material thickness (d) and frequency (f) [5]. According to the transmission line theory [6,7], relative complex permeability and permittivity are 2 essential factors in determining the performance of RAM absorption.

In general, the basic ingredients of RAM include magnetic materials such as ferrite, nickel, cobalt, and dielectric materials. For example, carbon and conductive polymers. Natural iron oxide compounds $\left(\mathrm{Fe}_{3} \mathrm{O}_{4}\right.$ and $\left.\mathrm{Fe}_{2} \mathrm{O}_{3}\right)$ can be found in large quantities in the form of iron sand. Research efforts to increase the economic and technological added value of iron sand began by making it a permanent magnet after ferrite $\left(\mathrm{Fe}_{3} \mathrm{O}_{4}\right)$ was separated from the non-magnetic components [8]. In the last 5 years, studies on RAM using magnetic materials, especially ferrite and barium hexaferrite, have been widely carried out [8-10]. 
Coconut shell was the main material in this research; this material can be converted into various carbon compounds with graphenic content. Graphenic is a single sheet consisting of carbon atoms forming a hexagonal bonding. Graphene and its derivates can be applied as RAM because of its extraordinary physical and chemical properties, such as superior electrical conductivity, large surface area, and excellent structural flexibility [7-11]. At present, research on the synthesis of rGO, such as carbon compounds from old coconut shells, has been widely developed because rGO is a derivative of graphene materials [12,13].

In the last 2 decades, several studies have been conducted on the design methods and techniques of RAM, such as design optimization using optimized genetic algorithms (GA), transmission line analogs (TLA) and equivalent circuit analog (ECA) $[14,15]$. The purpose of this study is to determine a thickness optimization program using GA to design a RAM with $R L$ below $-20 \mathrm{~dB}$ in the $\mathrm{X}$-band. This optimization is based on the transmission line model [16] of a material that is amplified by a single-layer RAM. As a test sample for RAM in this study, we selected a graphenic-based (rGO-like) carbon compound derived from biomass (coconut shell). Several studies have examined the design of microwave absorber at X-band frequencies using MATLAB, with input program, among others, $\varepsilon_{r}, \mu_{r}, f$ and $d$. The total thickness of the double-layer absorber [16] varies from 3 to $5.4 \mathrm{~mm}$ with a step size of $0.5 \mathrm{~mm}$. Meanwhile, the thickness of the single-layer absorber [17] varies from 2 to $6 \mathrm{~mm}$. In this study, the design of single-layer RAM from natural materials, derived from old coconut shell, is focused on optimizing the thickness of the single-layer absorber which is optimized using GA at the desired frequency. This thickness optimization can predict the appropriate thickness so that the optimum reflection loss can be obtained.

\section{Materials and methods}

In order to obtain maximum results, old coconut shells were dried in the sun for a day and burned to form black charcoal. The ingredients were then mashed with a mortar and then sieved with a mesh 200 to form a charcoal powder. This powder was then put into a container for carbonization. The installation process used a furnace with a holding time of $5 \mathrm{~h}$ at a temperature of $400{ }^{\circ} \mathrm{C}$ [18].

The chemical exfoliation process was conducted by mixing $100 \mathrm{~mL}$ of $1 \mathrm{M} \mathrm{HCl}$ solution with the powder, which was previously put through the manufacturing process. The solution was then stirred using a magnetic stirrer at a temperature of $70{ }^{\circ} \mathrm{C}$ for $20 \mathrm{~h}$, with a rotating speed of $350 \mathrm{rpm}$. The variation used in this study was the mole ratio between $1 \mathrm{M} \mathrm{HCl}$ solution and the powder, which was $1: 1$.

Next, a mechanical exfoliation was conducted using an ultrasonic cleaner for $6 \mathrm{~h}$ to cut the stacked graphenic sheets to produce thinner sheets. The steps in this study were divided into 2 stages. The first one involved characterization before exfoliation. This step included X-ray fluorescence (XRF), composition analysis (CHON) and X-ray diffractometry (XRD) for phase analyses. The second characterization was performed after the exfoliation, covering morphological structure analysis using scanning electron microscopy (SEM), an atomic force microscope (AFM) and the reflection loss $(R L)$ measurement employing a vector network analyzer (VNA). The $R L$ was determined by the S-parameter values $\left(\mathrm{S}_{11}\right.$ or $\left.\mathrm{S}_{22}\right)$ of the sample with a thickness of $2 \mathrm{~mm}$.

A schematic diagram of a sample system consisting of a conductor reinforced by a single-layer RAM that has intrinsic properties, $\mu_{\mathrm{r} 1}$ (relatively complex permeability), $\varepsilon_{\mathrm{r} 1}$ (relatively complex permittivity), $\eta, \gamma$ and $d_{l}$ (thickness) has been provided in Figure 1. The front surface of the sample was assumed to be a vacuum and the rear surface a metal plate. The input impedance on the surface of the air-absorbent and the calculation of the $R L$ for the sample system have been provided as follows [1]:

$R L=20 \log \left|\frac{Z_{i n}-1}{Z_{i n}+1}\right| \mathrm{z}$

$R L=20 \log \left|\frac{\sqrt{\mu_{r 1} / \varepsilon_{r 1} \tanh \left(j \frac{2 \pi f}{c}\right) \sqrt{\mu_{r 1} \varepsilon_{r 1}}} d_{1}-1}{\sqrt{\mu_{r 1} / \varepsilon_{r 1}} \tanh \left(j \frac{2 \pi f}{c}\right) \sqrt{\mu_{r 1} \varepsilon_{r 1}} d_{1}+1}\right|$

In Eqs. (1) - (2), $Z_{\text {in }}$ represents the characteristic impedance, $\varepsilon_{r 1}$ the relative complex permittivity $\left(\varepsilon_{r 1}=\varepsilon^{\prime}-j \varepsilon^{\prime \prime}\right), \mu_{r 1}$ the relative complex permeability $\left(\mu_{r 1}=\mu^{\prime}-j \mu^{\prime \prime}\right), f$ the frequency of electromagnetic waves, $c$ the speed of light in vacuum, and $d_{1}$ is the thickness of the material [19]. 


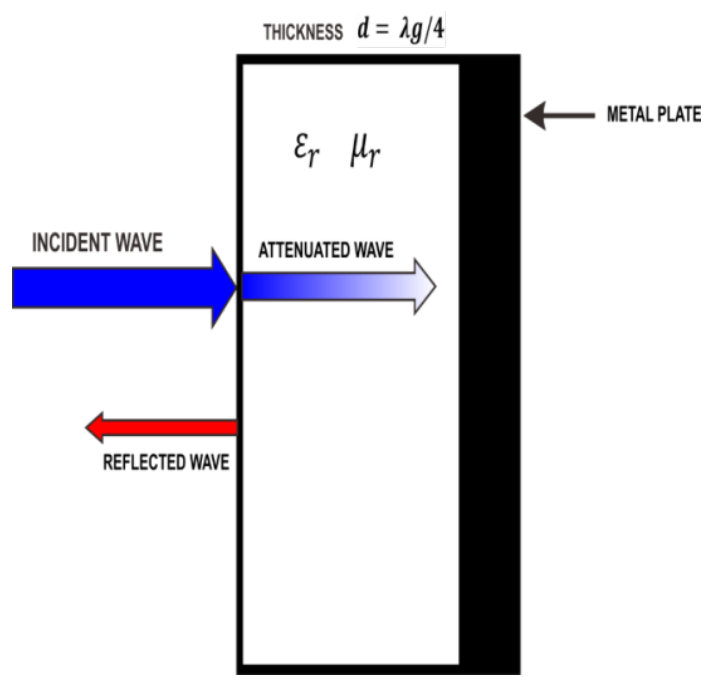

Figure 1 Schematic diagram of a single-layer RAM (Dallenbach layer).

From the above formula (Eq. (2)), it can be seen that $R L$ depends on $\mu_{r 1}, \varepsilon_{r 1}$ and thickness $\left(d_{1}\right)$ of the single-layer. A thickness optimization program was $\mu_{r 1}$ developed using GA. In this program, the optimization results were limited to a maximum thickness of $6 \mathrm{~mm}$. $R L$ from the optimization results was obtained by determining the thickness optimization using GA. The purpose of thickness optimization was to obtain the optimal $R L$ in a single layer of RAM in the $9-12 \mathrm{GHz}$ frequency range. The optimization parameters of GA consisted of population size, probability of crossing, and the probability of mutation. For the input, variables included the number of generations (maxgen), fitness threshold (fthreshold), frequency, speed of light, relative complex permeability and relative complex permittivity. The relative permittivity and permeability values were obtained by converting the S-parameter values $\left(S_{11}\right.$ and $\left.S_{21}\right)$ from VNA (experiment result) using the Nicolsson Ross Weir (NRW) method developed by the MATLAB program. The output variable of this study was the thickness of the sample. The $R L$ was then calculated using Eq. (2) by inputting parameter values such as relative complex permeability, relative complex permittivity, frequency of electromagnetic waves, speed of light in vacuum and thickness optimization results.

\section{Results and discussion}

\section{Structural analyses}

The samples of the charcoal powder that were obtained from an old coconut shell by burning it in a free-air environment were characterized using a PANalytical XRD with a range of $2 \theta$ intervals up to $60^{\circ}$ to identify the phases formed. The XRD pattern in Figure 2 shows two broad diffraction peaks centering at $\sim 23$ and $\sim 44^{\circ}$, which characterizes a compound close to the reduced graphene oxide (rGO) [18].

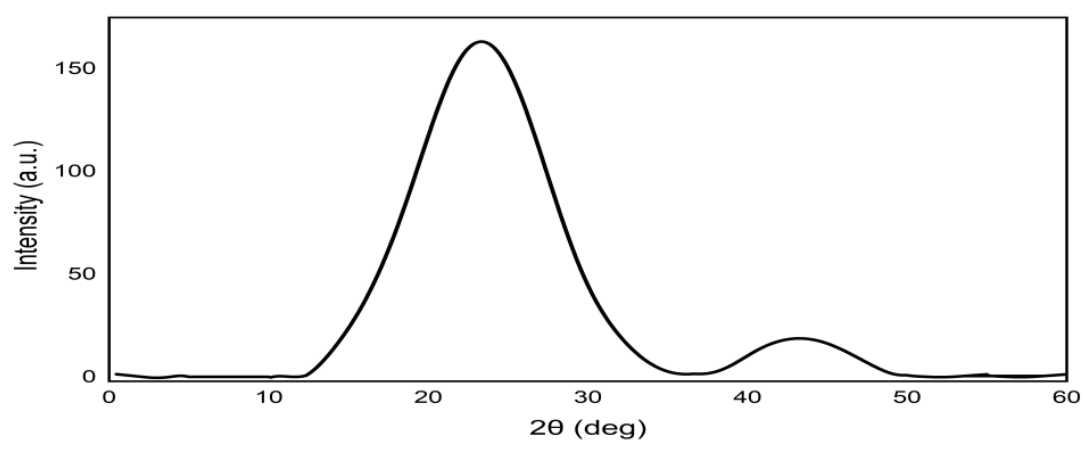

Figure 2 The XRD pattern of the sample 
Characterization using CHONS and XRF was performed to analyze the elemental content of the powder. This was aimed at analyzing the weight ratio of $\mathrm{C}, \mathrm{H}, \mathrm{O}, \mathrm{N}$ and $\mathrm{S}$ (the main constituent elements of carbon compound). Meanwhile, an XRF test was conducted to analyze the weight percentages of elements with larger atomic numbers (as impurities). The results of the 2 tests showed that there were 15 elements in the sample: $\mathrm{C}(53.65 \%), \mathrm{O}(34.08 \%)$ and $\mathrm{H}(6.26 \%)$. Further, other elements such as $\mathrm{N}, \mathrm{K}$, $\mathrm{P}$, etc. were labelled as impurities because their content was not appreciable. According to a previous report [20], a higher content of carbon and oxygen $(81.48 \%$ and $9.02 \%)$ were found in charcoal powder from an old coconut shell that was heated at $1000{ }^{\circ} \mathrm{C}$ for $5 \mathrm{~h}$. These results indicate that oxygen reduction occurred with heating at a higher temperature.

The morphological structure of the sample after the exfoliation process, as demonstrated in Figure 3 (a), showed plate-like particles being possibly constituted by many layers of hexagonal carbon bonds (graphenic phase). Further, on inspecting the particle size using an AFM (Figure 3(b)), it is seen that the thickness of a particle is about $1 \%$ compared to its lateral size, indicating that the particle is a very thin plate with a stacking of approximately 10 layers of graphenic sheets. This reduction in particle size of the powder can probably be attributed to the chemical exfoliation method (addition of a strong acid such as $\mathrm{HCl}$ ) and mechanical process (employing an ultra-sonication technique) [20] and heating at $400{ }^{\circ} \mathrm{C}$ for $5 \mathrm{~h}[20]$. This thin plate of the graphenic compound results in high efficiency in terms of the adsorption process and the ability to modify the material into a highly flattened surface [21].

The graphenic compound prepared through chemical and mechanical exfoliation contains a large amount of oxygen and residual group defect [19,22-2-5]. The FTIR characterization showed that the sample contains the main molecular bonds of a hexagonal (honeycomb) structure, such as $\mathrm{C}-\mathrm{C}$ and $\mathrm{C}=\mathrm{C}$ bonds, and other bonds (as impurities/defects), such as $\mathrm{C}-\mathrm{H}, \mathrm{C}-\mathrm{O}, \mathrm{C}=\mathrm{O}$ and $\mathrm{O}-\mathrm{H}$, confirming that the sample is close to the rGO-like structure [12-18]. The presence of these "impurity" bonds can be considered a source of electric dipoles. Furthermore, the formation of a magnetic moment is also possible, owing to heating at $400{ }^{\circ} \mathrm{C}$ to create a number of dangling bonds with unpaired electrons [26]. The electric dipole, along with the magnetic moment, is responsive to electromagnetic waves to induce absorption or $R L[18,19,26]$.

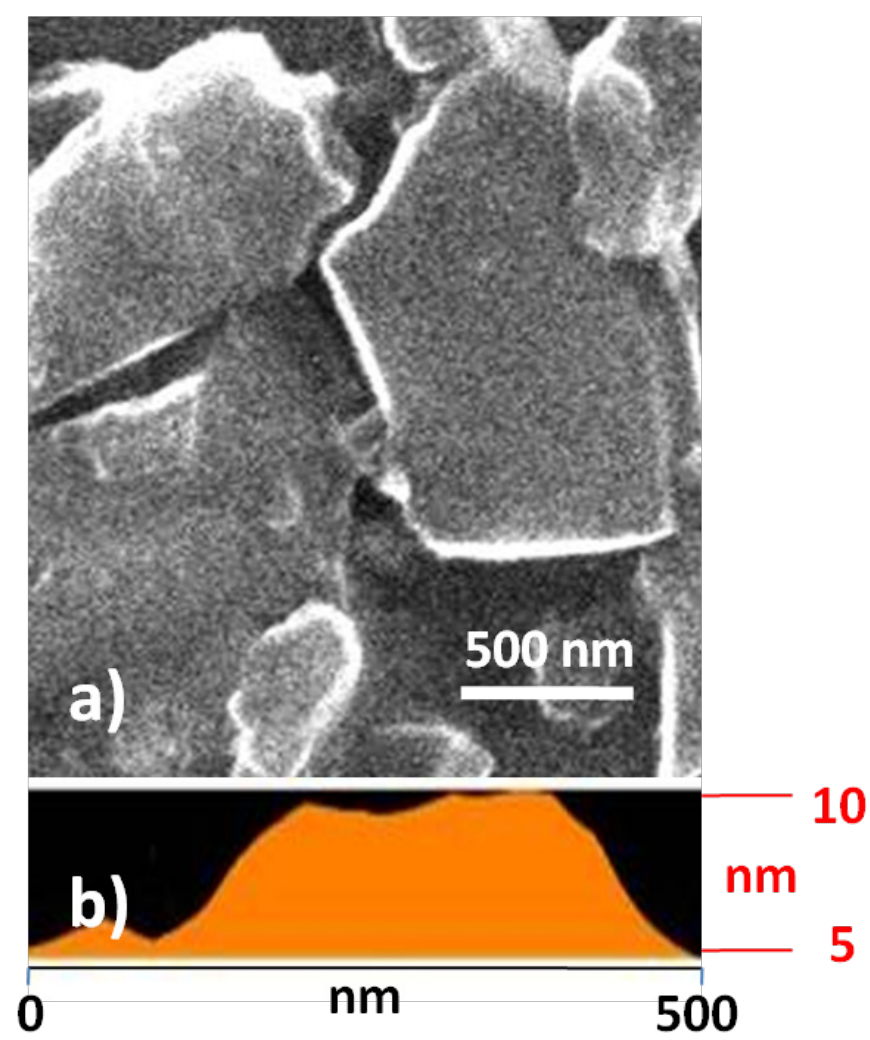

Figure 3 The structure of the graphenic-carbon sample after exfoliation observed using (a) SEM and (b) AFM's topographic profile. 


\section{Reflection loss optimization and measurement}

Figure 4 shows the relative real and imaginary complex permeabilities of the sample at 9-12 GHz. Relative real complex permeability is a measure of magnetic energy from external electromagnetic waves that are transmitted to the material, whereas relative imaginary complex permeability is magnetic energy from electromagnetic waves that is lost $[19,27,28]$. The values of real and imaginary complex permeability are relatively constant at a frequency range of about $\sim 10.25-11.5 \mathrm{GHz}$. These results are considered insignificant for the sample because of the weak magnetic characteristics [29].

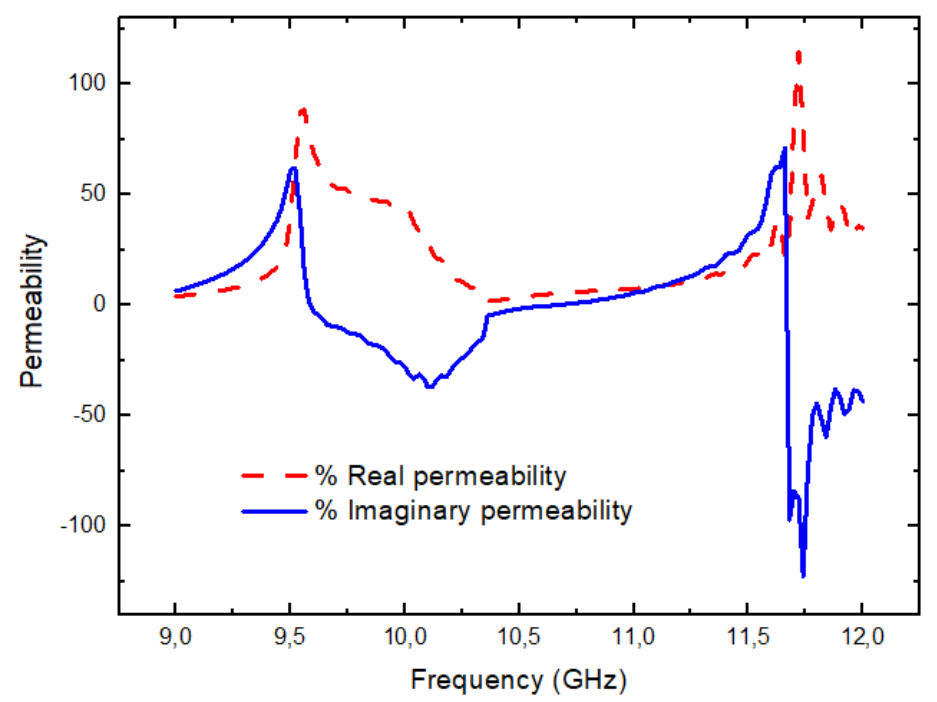

Figure 4 The real and imaginary parts of complex permeability

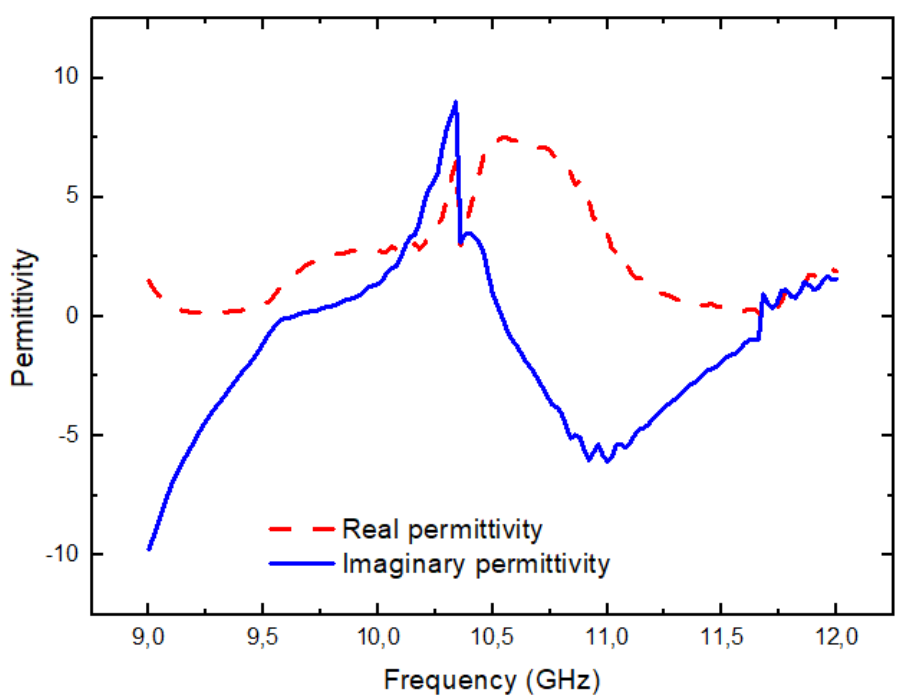

Figure 5 The real and imaginary parts of complex permittivity

Figure 5 shows that the sample had a strong ability to absorb and release microwave energy at $\sim 10.25-11.75 \mathrm{GHz}$. Real complex permittivity is a measure of electrical energy from external electromagnetic waves that can be passed on to the material, whereas imaginary complex permittivity is the electrical energy of a lost electromagnetic wave $[19,27,28]$. Notably, the amount of $R L$ (ability to absorb microwaves) depends on the values of complex permeability, which can be calculated using Eqs. (1) - (2). As permeability (magnetic loss) is weak, permittivity (dielectric loss) plays a dominant role 
in the absorption of the material [29]. Another that determines in the amount of $R L$ is impedance suitability. An absorber that has a high permittivity greatly influences the suitability of the impedance, resulting in strong reflection and weak absorption [30].

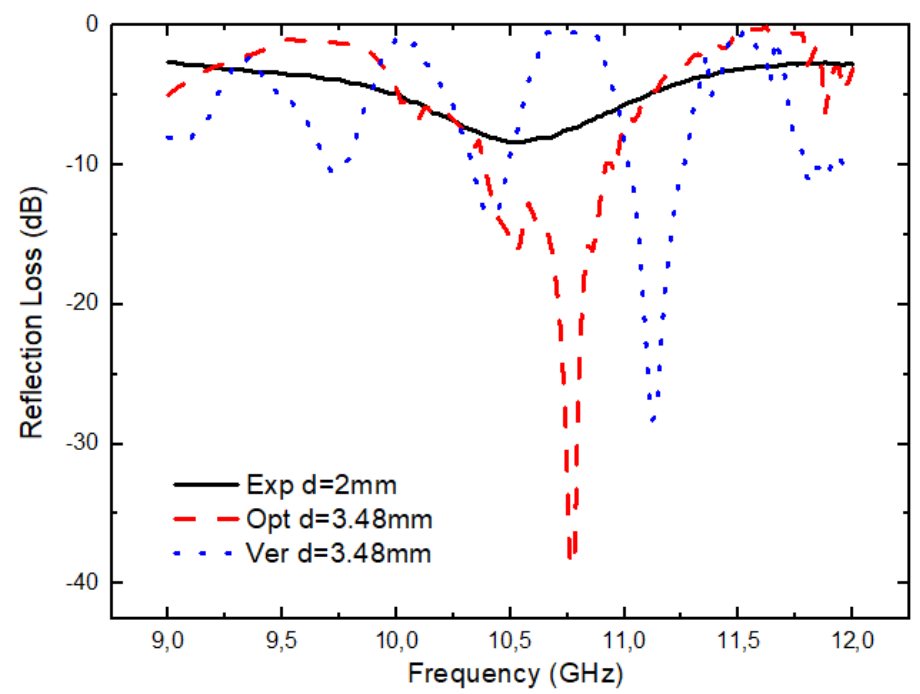

Figure 6 Experiment, optimization and verification of results

Figure 6 shows the $R L$ values from the measurement of the sample using VNA, optimization using GA and verification of results (re-measuring with optimized thickness) using the single-layer approach. The $R L$ of the experiment and verification results are obtained from characterization using the same setup of VNA. To find out the absorption value of microwaves from a material with a thickness of $2 \mathrm{~mm}$, the $R L$ value was measured $\left(\mathrm{S}_{11}\right.$ or $\left.\mathrm{S}_{22}\right)$. The greater the negative value of the $R L$, the greater the material's absorption of microwaves that hit it. From Figure 6, it can be concluded that the material in this study is reasonable for RAM.

To summarize, the $R L$ (according to Eq. (2)) is utilized by finding the values of complex relative permeability and complex relative permittivity, characterizing a type of material, with the MATLAB program, based on the NRW conversion method (program input incudes S-parameter values $\mathrm{S}_{11}$ and $\mathrm{S}_{21}$ ). The values were then entered into the program to obtain the $R L$ value (Eq. (2)) for a single-layer if the $R L$ value and the frequency between experiment and calculation were almost the same and showed a similar pattern. Furthermore, by knowing the value of relative complex permeability, the relative complex permittivity of the material can be further developed through thickness optimization, which aims to find the maximum $R L(<-20 \mathrm{~dB})$ using GA.

The results were verified by measuring the $R L$ based on the thickness of the optimization result (3.48 mm). A thicker or thinner sample does not always produce maximum $R L$. For example, a sample with thickness of $3.48 \mathrm{~mm}(R L \sim-38.77 \mathrm{~dB}$, at $10.78 \mathrm{GHz})$ shows a better $R L$ than a sample with a thickness of $5.99 \mathrm{~mm}(R L$ of $-32.45 \mathrm{~dB}$ at $10.62 \mathrm{GHz})$ and $1.41 \mathrm{~mm}(R L-30.76 \mathrm{~dB}$ at $10.94 \mathrm{GHz})$. Maximum absorption power is obtained by aligning the frequency and thickness. The relation between $R L$ and layer thickness is induced through the mutually weakening mechanism between the incident and reflected waves. An electromagnetic wave that can reach the base of the material will reflect off the conductor plate. At the proper/optimal thickness, reflected waves will have the opposite phase $\left(180^{\circ}\right)$ with the incident one. Therefore, there will be a weakening of the incident wave. In this case, a material may have $\left|\mu_{\mathrm{r}}\right|>\left|\varepsilon_{\mathrm{r}}\right|$ or $\left|\mu_{\mathrm{r}}\right|<\left|\varepsilon_{\mathrm{r}}\right|$.

By optimization, the maximum $R L$ can be predicted at the desired frequency. Thickness optimization begins by entering the value of relatively complex permeability and permittivity, as results from convertion by using the NRW method from single-layer VNA data $\left(\mathrm{S}_{11}\right.$ or $\left.\mathrm{S}_{22}\right)$ of the sample at the desired frequency. Further, with the GA program, the thickness value is obtained to produce the optimal reflection value at the desired frequency. Afterward, $R L$ optimization can be calculated again based on the optimal thickness value. In Figure 6, the $R L$ optimization chart tends to show the same trend as the $R L$ verification curve. The maximum peak of $R L$ by optimization is generally approached through 
verification. Notably, the maximum peak frequency in optimization $(10.78 \mathrm{GHz})$ and verification $(11.12$ $\mathrm{GHz}$ ) shows no significant difference.

Several recent studies, such as that conducted by Refs. [31] reported the optimization of the doublelayer microwave absorber Graphene / epoxy nanocomposite material with various weight percentages using the non-dominated sorting genetic algorithm -II (NSGA-II) method which produced the optimum $R L$ value $-28.29 \mathrm{~dB}$ at the X-band frequency. Meanwhile, authors in Ref. [32] described modeling with a microwave absorber computer design based on experimental studies on single-layer and double-layer $\mathrm{CuO}$ and $\mathrm{CuO}$-containing graphene nanoparticle (GNP) samples. Double-layer composite produces an optimum $R L$ of $-33.7 \mathrm{~dB}$ at a frequency of $10.06 \mathrm{GHz}$. In short, the single-layer microwave absorber demonsrated in this study is able to produce a higher optimum $R L$ than the double-layer microwave absorbers in both previous report mentioned above.

\section{Conclusions}

The powder of an old coconut shell was successfully prepared via a process of combustion in a controlled atmosphere. The shell was heated at $400{ }^{\circ} \mathrm{C}$ and exfoliated using a 1:1 mole HCl-aquadest solution. The sample that contained a graphenic (rGO-like) carbon compound was characterized as a radar absorber. The optimum thickness of the sample, the maximum peak value of $R L$, and the maximum peak frequency in optimization and verification are $3.48 \mathrm{~mm}, \uparrow-38.77 \mathrm{~dB}, 10.78 \mathrm{GHz},-28.32 \mathrm{~dB}$ and $11.12 \mathrm{GHz}$, respectively. The material used in this research is considered to be a good RAM because it has a strong ability to absorb the X-band microwaves. No significant difference in the maximum peak of $R L$ in optimization and verification was found. It should be noted that thickness optimization to produce maximum $R L$ is very important before conducting an effective and efficient experiment.

\section{Acknowledgements}

This research was supported by a scholarship for a doctoral study, Lembaga Pengelola Dana Pendidikan Beasiswa Unggulan Dosen Indonesia Dalam Negeri (LPDP BUDI-DN), from the Ministry of Finance, Indonesia (AFK), and by Hibah Konsorsium Riset Unggulan Perguruan Tinggi (KRUPT) 2019 from the Ministry of Research, Technology, and Higher Education, Indonesia.

\section{References}

[1] JP Gogoi, NS Bhattacharyya and S Bhattacharyya. Single layer microwave absorber based on expanded graphite-novolac phenolic resin composite for X-band applications. Compos. B Eng. 2014; 58, 518-23.

[2] EY Jung, JW Lee, TK Lee and WK Lee. SIW-based array antennas with sequential feeding for Xband satellite communication. IEEE Trans. Antennas Propag. 2012; 60, 3632-9.

[3] A Damini, M McDonald and GE Haslam. X-band wideband experimental airborne radar for SAR, GMTI and maritime surveillance. IEE Proc. Radar Sonar Navig. 2013; 150, 305-12.

[4] SM Hanna. Applications of X-band technology in medical accelerators. 1999 particle accelerator conference. In: Proceedings of the 1999 Particle Accelerator Conference, New York, USA. 1999, p. 2516-8.

[5] E Michielssen, JM Sajer, S Ranjithan and R Mittra. Design of lightweight, broad-band microwave absorbers using genetic algorithms. IEEE Trans. Microw. Theor. Tech. 1993; 41, 1024-31.

[6] A Oikonomou, T Giannakopoulou and G Litsardakis. Design, fabrication and characterization of hexagonal ferrite multi-layer microwave absorber. J. Magn. Magn. Mater. 2007; 316, e827-e830.

[7] Y Yin, M Zeng, J Liu, W Tang, H Dong, R Xia and R Yu. Enhanced high-frequency absorption of anisotropic $\mathrm{Fe}_{3} \mathrm{O}_{4}$ /graphene nanocomposites. Sci. Rep. 2016; 6, 25075.

[8] Mashuri. 2012, Partikel nano $\mathrm{Ni}_{0,5} \mathrm{Zn}_{0,5} \mathrm{Fe}_{2} \mathrm{O}_{4}$ Berbahan Baku $\mathrm{Fe}_{3} \mathrm{O}_{4}$ Dari Pasir Besi Sebagai Bahan Penyerap Gelombang Mikro Pada Frekuensi Tinggi. Ph. D. Dissertation. Institut Teknologi Sepuluh Nopember, Surabaya, Indonesia.

[9] I Kong, SH Ahmad, MH Abdullah, D Hui, AN Yusoff and D Puryanti. Magnetic and microwave absorbing properties of magnetite-thermoplastic natural rubber nanocomposites. J. Magn. Magn. Mater. 2010; 322, 3401-3409.

[10] KC Tripathi, SM Abbas, PS Alegaonkar and RB Sharma. Microwave absorption properties of NiZn ferrite nano-particle based nano composite. Int. J. Adv. Res. Sci. Eng. Technol. 2015; 2, 463-8.

[11] X Zeng, B Yang, H Yang, L Zhu and R Yu. Solvothermal synthesis and good microwave absorbing properties for magnetic porous- $\mathrm{Fe}_{3} \mathrm{O}_{4} /$ graphene nanocomposites. AIP $A d v .2017 ;$ 7, 056605. 
[12] AY Nugraheni, M Nasrullah, FA Prasetya, F Astuti and Darminto. Study on phase, molecular bonding, and bandgap of reduced graphene oxide prepared by heating coconut shell. Mater. Sci. Forum 2015; 827, 285-9.

[13] Kurniasari, A Maulana, AY Nugraheni, DN Jayanti, S Mustofa, MA Baqiya and Darminto. Defect and magnetic properties of reduced graphene oxide prepared from old coconut shell. IOP Conf. Ser.: Mater. Sci. Eng. 2017; 196, 012021.

[14] RA Stonier. Stealth aircraft \& technology from World War II to the gulf. Part I: History and background. SAMPE J. 1991; 27, 9-17.

[15] B Chambers and A Tennant. Optimised design of Jaumann radar absorbing materials using a genetic algorithm. IEE Proc. Radar Sonar Navig. 1996; 143, 23-30.

[16] JP Gogoi and NS Bhattacharyya. Expanded graphite-phenolic resin composites based double layer microwave absorber for X-band applications. J. Appl. Phys. 2014; 116, 204101.

[17] JP Gogoi. 2012, Expanded graphite-novolac phenolic resin based electromagnetic interference (EMI) shielding material over the X-band: Synthesis, characterization, analysis and design optimization. Ph. D. Dissertation. Tezpur University, Assam, India.

[18] AF Kurniawan, MS Anwar, K Nadiyyah, Mashuri, Triwikantoro and Darminto. Mechanical exfoliation of reduced graphene oxide from old coconut shell as radar absorber in X-band. Mater. Sci. Forum 2019; 966, 25-9.

[19] E Handoko, S Iwan, S Budi, BS Anggoro, AM Mangasi, M Randa, J Zulkarnain, C Kurniawan, N Sofyan and $\mathrm{M}$ Alaydrus. Magnetic and microwave absorbing properties of $\mathrm{BaFe}_{12-2 \mathrm{x}} \mathrm{Co}_{\mathrm{x}} \mathrm{Zn}_{\mathrm{x}} \mathrm{O}_{19}(\mathrm{x}$ $=0.0 ; 0.2 ; 0.4 ; 0.6)$ nanocrystalline. Mater. Res. Express $2018 ; 5,064003$.

[20] W Islamiyah, L Nashirudin, MA Baqiya, Y Cahyono and Darminto. Sulfuric acid intercalatedmechanical exfoliation of reduced graphene oxide from old coconut shell. Advancing innovation in materials science, technology and applications for sustainable future. In: Proceedings of the $3^{\text {rd }}$ International Conference on Materials and Metallurgical Engineering and Technology, Surabaya, Indonesia. 2017, p. 020054.

[21] A Esteban-Arranz, D Compte-Tordesillas, V Muñoz-Andrés, M Pérez-Cadenas and A GuerreroRuiz. Effect of surface, structural and textural properties of graphenic materials over cooperative and synergetic adsorptions of two chloroaromatic compounds from aqueous solution. Catal. Today 2018; 301, 104-11.

[22] S Park and RS Ruoff. Chemical methods for the production of graphenes. Nat. Nanotechnol. 2009; 4, 217-24.

[23] MJ Allen, VC Tung and RB Kaner. Honeycomb carbon: A review of graphene. Chem. Rev. 2010; 110, 132-45.

[24] S Stankovich, DA Dikin, RD Piner, KA Kohlhaas, A Kleinhammes, Y Jia, Y Wu, ST Nguyen and RS Ruoff. Synthesis of graphene-based nanosheets via chemical reduction of exfoliated graphite oxide. Carbon 2007; 45, 1558-65.

[25] JI Paredes, S Villar-Rodil, A Martínez-Alonso and JMD Tascón. Graphene oxide dispersions in organic solvents. Langmuir 2008; 24, 10560-4.

[26] Darminto, Y Koike, R Asih, Kurniasari, MA Baqiya, S Mustofa, Suasmoro, T Kawamata, M Kato and I Watanabe. Enhanced magnetism by temperature induced defects in reduced graphene oxide prepared from coconut shells. IEEE Trans. Magn. 2018; 54, 1600105.

[27] B Zhao, W Zhao, G Shao, B Fan and R Zhang. Morphology-control synthesis of a core-shell structured $\mathrm{NiCu}$ alloy with tunable electromagnetic-wave absorption capabilities. ACS Appl. Mater. Interfaces 2015; 7, 12951-60.

[28] B Zhao, G Shao, B Fan, W Zhao and R Zhang. Facile synthesis and enhanced microwave absorption properties of novel hierarchical heterostructures based on a Ni microsphere-CuO nanorice core-shell composite. Phys. Chem. Chem. Phys. 2015; 17, 6044-52.

[29] C Wang, X Han, P Xu, X Zhang, Y Du, S Hu, J Wang and X Wang. The electromagnetic property of chemically reduced graphene oxide and its application as microwave absorbing material. Appl. Phys. Lett. 2011; 98, 072906.

[30] RC Che, LM Peng, XF Duan, Q Chen and XL Liang. Microwave absorption enhancement and complex permittivity and permeability of Fe encapsulated within carbon nanotubes. Adv. Mater. 2004; 16, 401-5.

[31] B Santhosi, K Ramji and NBRM Rao. Optimization of double layered graphene-based microwave absorber in X-band using pareto genetic algorithm. Mater. Res. Express 2019; 6, 105610.

[32] Y Akinay and AO Kizilcay. Computation and modeling of microwave absorbing $\mathrm{CuO} / \mathrm{graphene}$ nanocomposites. Polym. Compos. 2020; 41, 227-32. 